\title{
A PERSISTÊNCIA E SIGNIFICADO DA PAISAGEM DO CENTRO HISTÓRICO DE CIDADES DE PEQUENO PORTE: REGENTE FEIJÓ, SP
}

\author{
Beatriz Fernandes Bastos; Hélio Hirao \\ Universidade Estadual Paulista - UNESP, Arquitetura e Urbanismo, Presidente Prudente, SP. PROPe (Pró-Reitoria de \\ Pesquisa)/Programa Renove - Iniciação Científica. E-mail: beatriz959@hotmail.com
}

\begin{abstract}
RESUMO
A pesquisa sobre a permanência das Paisagens iniciais no centro histórico de Regente Feijó, cidade localizada na região de Presidente Prudente, buscou identificar e mapear o conjunto de elementos arquitetônicos e urbanísticos históricos/culturais que caracterizam o centro desta cidade. Para isso, realizou-se visitas técnicas entrevistando os moradores e buscando documentação primária, como mapas, fotos e documentos históricos. Verificou-se que a fundação da cidade teve como determinante a "Estrada Boiadeira" e a linha férrea, similar às outras regiões, nas quais a chegada da estrada de ferro também impulsionou o desenvolvimento. Percebe-se a preservação de uma paisagem, mesmo com descaracterizações, que remete a ambiência dos núcleos iniciais comparticipando do cotidiano da cidade atual. Assim, o levantamento destes dados possibilitou subsídios para posteriores encaminhamentos de ações de sua salvaguarda, uma vez que caminhamos para a uma homogeneização das suas Paisagens.

Palavras-chave: Centro Histórico, Preservação, Paisagem Urbana, Paisagem Cultural, Patrimônio Histórico.

THE PERSISTENCE AND SIGNIFICANCE OF THE HISTORICAL CENTER'S LANDSCAPE OF SMALL CITIES: REGENTE FEIJÓ, SP
\end{abstract}

\begin{abstract}
The research about regarding the permanence of initial Landscapes in the historic center of Regente Feijó, a city in the region of Presidente Prudente, identify and map the historical/cultural set of significant architectural and urban elements that characterize the center of this city. For this, technical visits were done interviewing the residents and seeking information material such as maps, photos and historical documents. It was found that the "Boiadeira Road" and the railway line determined the foundation of Regente Feijó, similar to other regions in which the arrival of the railroad also boosted the development. There was the preservation of a landscape, even with mischaracterization, which refers the ambience of the initial center, that coparceners in the current city. Thus, the survey of these data allowed subsidies for further referrals of their safeguard actions, as we move towards a homogenization of Landscapes.
\end{abstract}

Keywords: Historic Center, Preservation, Urban Landscape, Cultural Landscape, Historical Heritage. 


\section{INTRODUÇÃO}

A investigação levanta e identifica a paisagem característica de Regente Feijó, cidade situada na região de Presidente Prudente, que ainda apresenta registros materiais do seu núcleo inicial de ocupação. Essas características históricas permanecem e definem o seu caráter e identificam a cidade.

A cidade é produto material dos recursos econômicos proporcionado pelo cultivo do café, algodão e amendoim e consequente avanço dos trilhos da Estrada de Ferro no Estado de São Paulo. Enquanto essas culturas procuraram novas terras férteis, abandonando as utilizadas a exaustão, nos núcleos urbanos iniciais, paisagens características dessa época foram produzidas com construções feitas de acordo com suas possibilidades econômicas, de material construtivo e mão de obra, criando fortes identidades locais.

Esses núcleos urbanos surgiram em frente a estação ferroviária com avenidas demarcando o limite da área urbana com a rural. A ideia de cidade se concretizou com a implantação dos equipamentos públicos como a praça, a prefeitura, a escola, a igreja, junto com o comércio e habitações em seu entorno, com um traçado quadriculado em forma de tabuleiro de xadrez.

Desse modo, esta investigação pretendeu identificar até que ponto 0 processo de abandono e deterioração, comum nos centros históricos das metrópoles e cidades médias, que tem como consequência a substituição de edifícios, praças e conjuntos deles por outros, descaracterizando o conjunto urbano inicial, também aconteceu ou não na cidade de Regente Feijó, possibilitando a produção de dados que subsidiem análises e reflexões que encaminhem ações e estratégias que garantam a preservação do caráter da cidade, considerando sua história e evolução.

\section{METODOLOGIA}

A investigação, inicialmente, realizou uma revisão bibliográfica abordando as questões ligadas a preservação do patrimônio histórico e cultural, subsidiados na teoria da restauração e nas cartas patrimoniais. Depois, analisou a temática das intervenções projetuais nos centros históricos de pequenas e médias cidades do interior do estado, verificando a evolução urbana da região visando compreender o processo urbano da cidade.

$\mathrm{Na}$ etapa seguinte, de campo, realizaram-se visitas técnicas a essa cidade para vivenciar e reconhecer as paisagens do centro histórico, realizando entrevistas com moradores da cidade, e buscando material informativo, como mapas, fotos e documentos históricos. Na sequência, fez-se o levantamento e identificação da paisagem 
da área central e seus equipamentos urbanos de interesse de preservação.

\section{RESULTADOS}

Para o estudo da expansão urbana de Regente Feijó, foram utilizadas as informações obtidas em três documentos: uma planta do traçado urbano de 1939, outra de 1993 e uma base cartográfica atual. Assim, a análise foi dividida nesses três recortes temporais (Fig. 1).

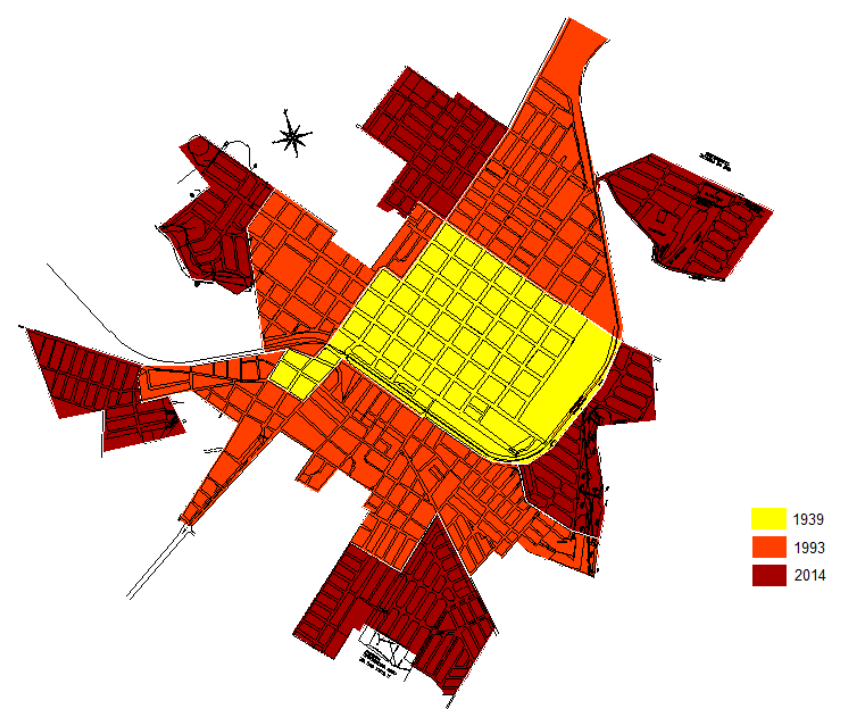

Figura 1. Os recortes

Fonte: B. F. Bastos, 2014

Dotada de avenidas e com traçado ortogonal, a área central da cidade foi planejada com quadras rigorosamente iguais, de 100 metros por 100 metros, com terrenos de 20 metros de testada e 30 metros de fundo, de $20 \times 40$ e de $20 \times 50$ (EMUBRA, 2003). Posteriormente, verifica-se a implantação de traçados irregulares de bairros mais recentes, com ruas estreitas e a localização dos conjuntos habitacionais (Fig. 2), distantes do tecido urbano consolidado.

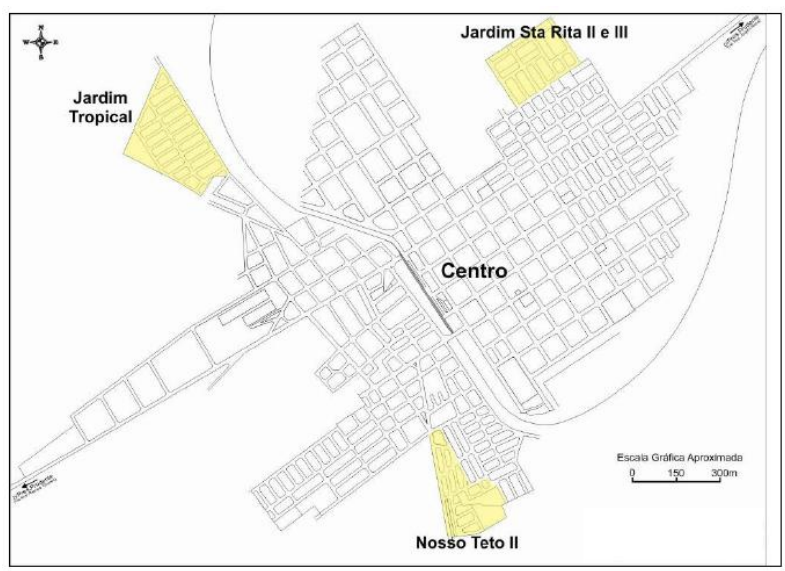

Figura 2. Localização dos bairros descontínuos e distantes do tecido urbano consolidado

Fonte: Miyazaki (2007), editado por B.F. Bastos

A tendência de expansão urbana ocorre de um dos lados dos trilhos - a lado da frente da estação - o que é recorrente em cidades que tiveram seu desenvolvimento associado à chegada da estrada de ferro (Fig. $3)$.

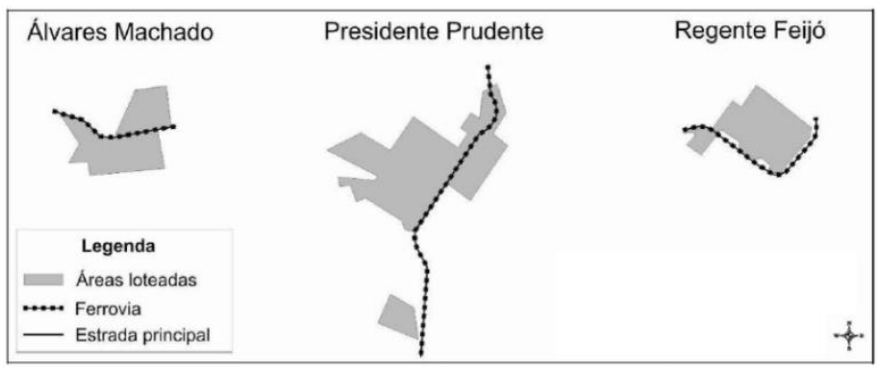

Figura 3. Áreas urbanas dos municípios em 1938, mostrando a tendência de crescimento para o lado da frente da estação ferroviária Fonte: Miyazaki (2007), editado por B.F. Bastos 
Regente Feijó teve seu crescimento limitado por carência de espaço. Um dos limites era a Fazenda Mandaguari (Fig. 4), uma grande fazenda de criação de gado, rica em lavoura e em café (EMUBRA, 2003).

Outro limite era a estrada de ferro, que circundava a cidade. Na Rua Paulo Harris havia pequenas chácaras próximas à linha as quais os proprietários não tinham interesse em lotear e vender os terrenos o que impedia a cidade de crescer, devido à falta de interesse pelos seus proprietários. Em frente à Rua Barão do Rio Branco e Brigadeiro Tobias, chegava-se na chácara Bonadia, também fechando a cidade (Fig. 5), e chegava-se até a estação.

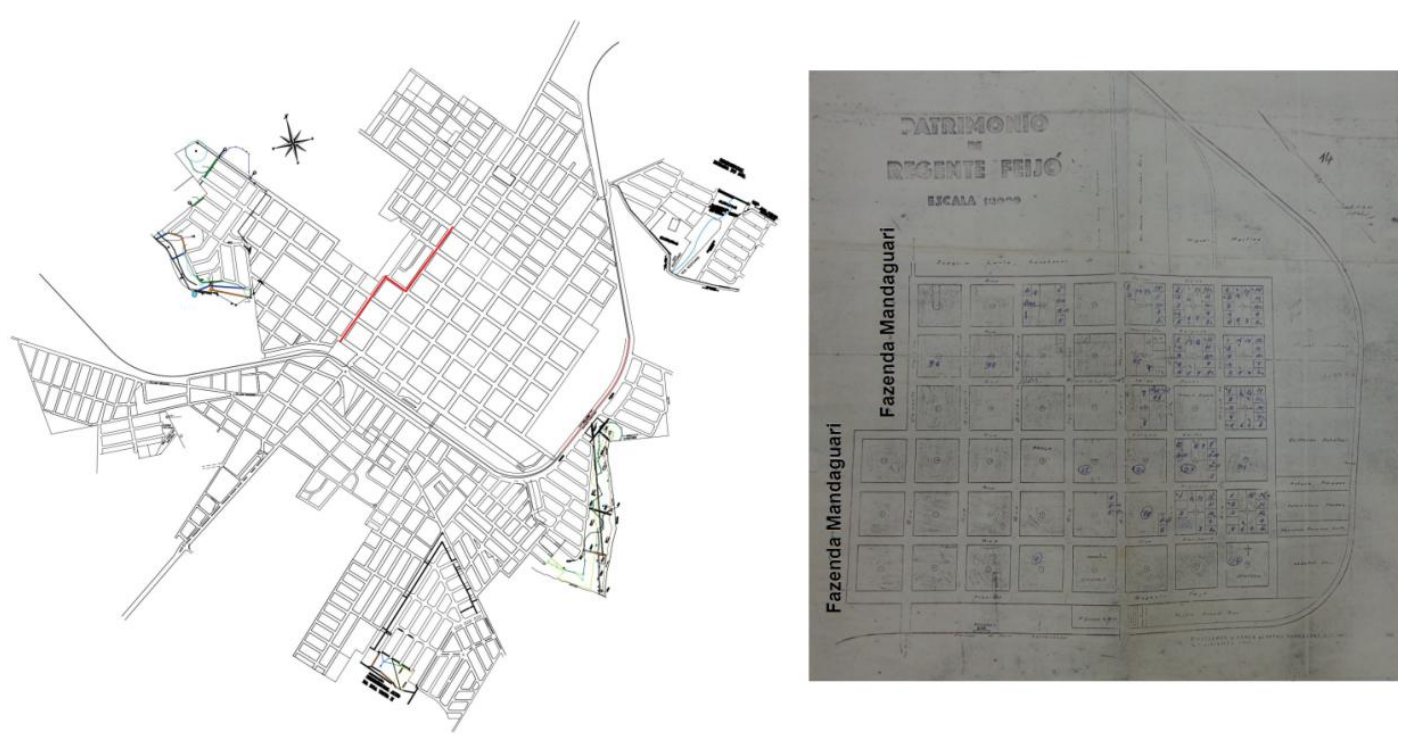

Figura 4. Localização da Fazenda Mandaguari (começava na linha em vermelho)

Fonte: Prefeitura Municipal de Regente Feijó (2014) e Cartório de Regente Feijó, editado por B.F. Bastos
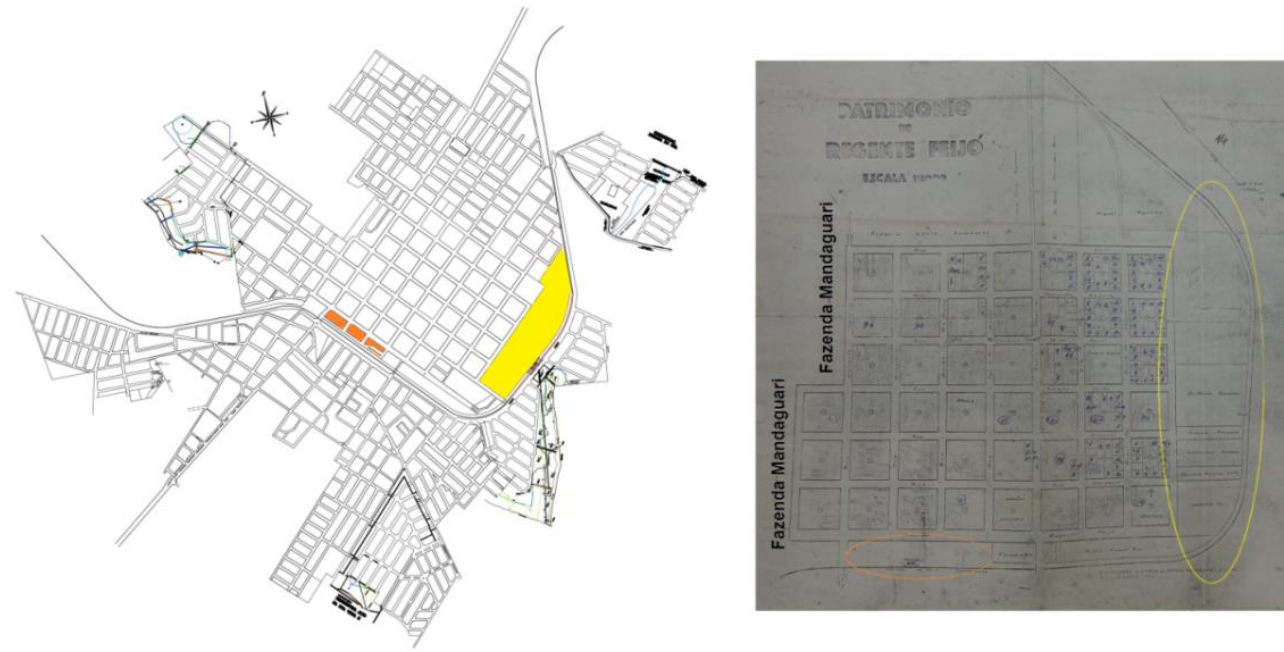

Figura 5. Pequenas chácaras próximas à linha (em amarelo) e chácara Bonadia (em laranja) Fonte: Prefeitura Municipal de Regente Feijó (2014) e Cartório de Regente Feijó, editado por B.F.Bastos 
No primeiro recorte observaram-se como elementos formadores do patrimônio histórico edifícios relacionados à estrada de ferro, como a estação ferroviária e os galpões de armazenamento, além dos equipamentos públicos que acompanham o surgimento de qualquer cidade, como a praça, a igreja e o cemitério, junto com o comércio e habitações em seu entorno.

No segundo recorte, foram identificados diversos elementos arquitetônicos e urbanísticos significativos que compõem a paisagem urbana de Regente Feijó e são importantes para a identidade da cidade. Entre eles, a rodoviária, a câmara municipal, o fórum, a Casa de Saúde, as escolas, a Biblioteca Pública Municipal, algumas indústrias e a máquina de beneficiamento de café e arroz.

No terceiro recorte, pode-se notar que alguns conjuntos habitacionais foram construídos. Entre estes, a Cecap, "O Nosso Teto 1" e o "Nosso Teto 2".

Identificou-se que a Avenida José Bonifácio é um eixo comercial da cidade, grande parte dos seus edifícios são antigos, e sempre teve essa característica de uso (Fig. 6). Porém, não é comercial em toda a sua extensão, depois da Rua Júlio de Mesquita se torna mista, isto é, com residências e alguns estabelecimentos de serviços, como clínicas, escritórios e raramente pequenos comércios, até se tornar totalmente residencial (Fig. 7). A importância desse eixo pode ser notada no tratamento que os moradores dão a ela, chamando-a de Avenida Central ou Rua do Centro.

As edificações predominantes nessa avenida apresentam características do Art déco, porém, algumas já foram totalmente ou parcialmente descaracterizadas.

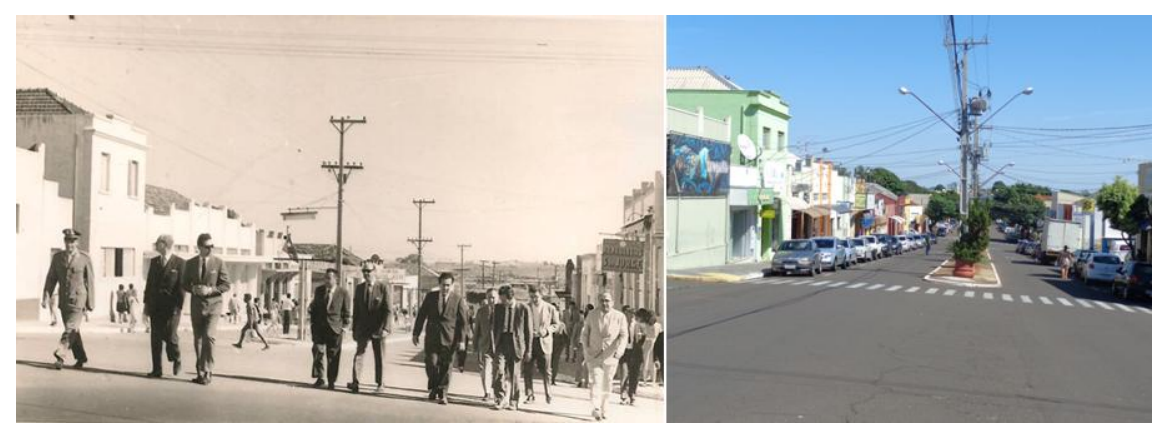

Figura 6. Fotos comparativas do mesmo ponto da Avenida José Bonifácio demonstrando que o caráter comercial permanece Fonte: Museu Municipal de Regente Feijó e B.F. Bastos 


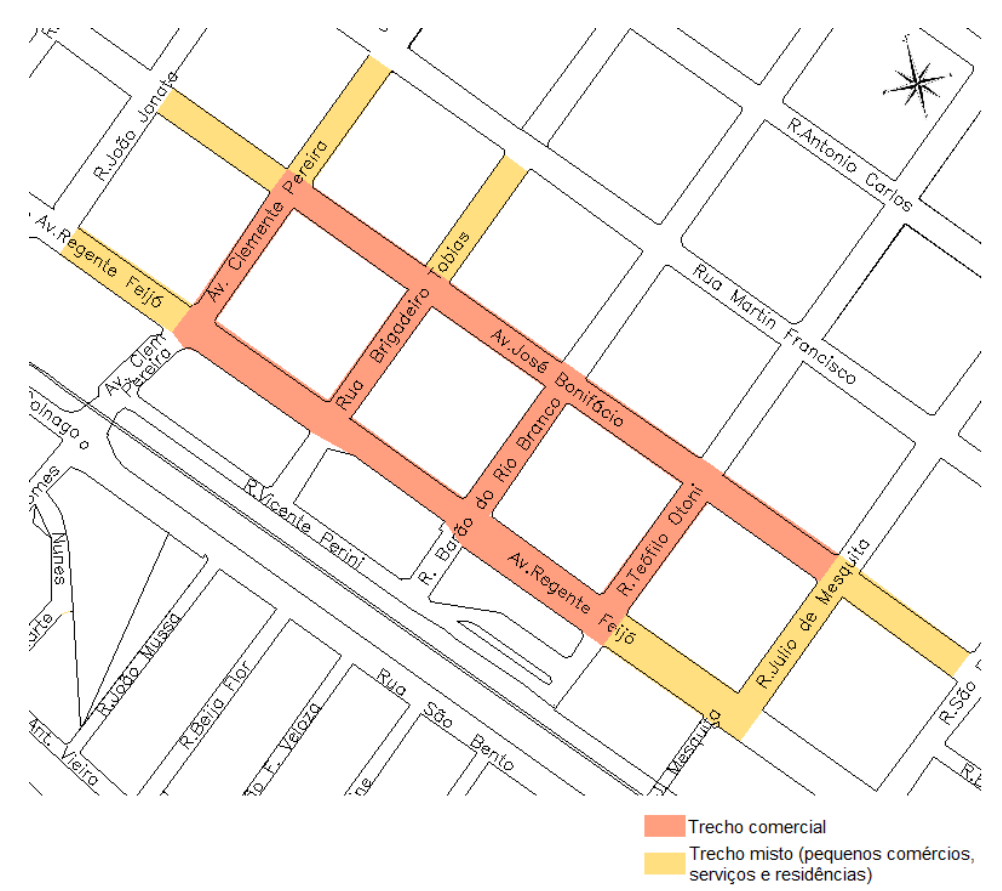

Figura 7. Localização dos usos comercial e misto

Fonte: Prefeitura Municipal de Regente Feijó, editado por B.F. Bastos (2014)

\section{DISCUSSÃO}

A pesquisa aponta para reflexão do encaminhamento das questões de preservação e salvaguarda do patrimônio arquitetônico e urbanístico das pequenas cidades do entorno de Presidente Prudente, como é o caso de Regente Feijó.

A linha férrea foi um dos determinantes da fundação de Regente Feijó e também serviu de guia para a delimitação do traçado urbano e da abertura de suas vias iniciais e principais, verifica-se configurações similares às outras da região. Porém, o vilarejo inicial que deu origem a Regente Feijó não teve sua demarcação feita apenas em função da ferrovia, mas também em função da "Estrada Boiadeira".
A chegada da estrada de ferro também impulsionou o desenvolvimento e conferiu a importância da cidade de Regente Feijó perante as cidades de sua região, pois facilitou a comunicação com São Paulo e com as cidades existentes no percurso, possibilitando o rápido escoamento das mercadorias.

A partir da análise fotográfica e de visitas à campo, constata-se que as edificações do núcleo inicial, principalmente as localizadas nas avenidas principais, Regente Feijó e José Bonifácio, encontram-se bem conservadas, em sua maioria, mas, apresentam a adição de letreiros nas fachadas, visto que predomina o uso comercial, como também apresentam alterações das aberturas de portas e janelas e 
modificação das cores das fachadas. Apesar disso, os detalhes característicos do Art-Déco não sofreram alterações. Não foi encontrado nenhum edifício em ruína, apenas alguns abandonados.

Percebe-se, então, a preservação de uma paisagem, mesmo com descaracterizações, que remete a ambiência dos núcleos iniciais. A estagnação econômica pode ter contribuído para essa permanência, que corre o risco de perder os suportes materiais da sua história, se não adequarem seus espaços para as novas necessidades da cidade atual com preocupações de manter suas características patrimoniais.

\section{CONCLUSÃO}

Pelo trabalho realizado percebe-se que para a salvaguarda da paisagem característica dos tempos iniciais do núcleo urbano são necessárias ações de educação patrimonial para conscientização da população da importância de seu patrimônio urbano e arquitetônico, bem como o planejamento e implantação de políticas públicas de preservação patrimonial, conciliando os vários interesses envolvidos, inclusive os do mercado imobiliário.

Desse modo, um amplo leque de assuntos para pesquisa se abre e com certeza, contribuirá para preservação do Patrimônio Histórico Arquitetônico e
Urbanístico das pequenas cidades do entorno de Presidente Prudente.

\section{REFERÊNCIAS}

EMUBRA. Regente Feijó, 2003. Disponível em:

<http://camarapprudente.sp.gov.br/historia/ hist_oeste/cidades/rfeijo/historia.html>.

Acesso em: 22 jan. 2015.

MIYAZAKI, V. K. Um Estudo sobre o processo de aglomeração urbana: Álvares Machado, Presidente Prudente e Regente Feijó. Presidente Prudente: 2008 -Dissertação -1 Mestrado) - FCT/ UNESP.

MUSEU Municipal de Regente Feijó. Disponível em: <https://www.facebook.com/profile.php?id= 100004847353199\&fref=ts>. Acesso em: 09 set. 2014.

Recebido para publicação em 04/08/2015 Revisado em 07/08/2015

Aceito em 11/08/2015 